\title{
A ABORDAGEM EPISTEMOLÓGICA DO FENÔMENO BULLYING NA PERSPECTIVA DE UM GRUPO DE PESQUISA
}

\author{
EPISTEMOLOGICAL APPROACH TO BULLYING FROM THE PERSPECTIVE OF \\ A RESEARCH GROUP
}

DOI: http://dx.doi.org/10.23926/RPD.2526-2149.2020.v5.n1.p489-501.id561

\section{Vanessa Costa Gonçalves Silva \\ Mestra em Ensino (IFMT/UNIC) \\ Pedagoga do Instituto \\ Federal de Mato Grosso (IFMT) \\ vanessa.silva@blv.ifmt.edu.b r}

\section{Raquel Martins \\ Fernandes}

Pós Doutorado em

Psicologia Social (UFPB)

Professora do Instituto

Federal de Mato Grosso

(IFMT)

raquel.fernandes@blv.ifmt.e du.br

\section{Paulo Alves de \\ Oliveira \\ Mestre em Ensino (IFMT/UNIC) \\ Técnico Administrativo do Instituto Federal de Mato Grosso (IFMT) paulo.oliveira@blv.ifmt.edu. br}

Resumo: O artigo é uma análise dos artigos científicos publicados pelo Grupo de Pesquisa em Humanidades e Sociedade Contemporânea do IFMT (GPHSC-IFMT), o recorte se deu entre os anos de 2016 e 2017, e analisou-se como as pesquisas realizadas pelo grupo de pesquisa inserem-se na propositura de múltiplas abordagens do bullying no cotidiano escolar (CERTEAU, $1994 \mathrm{e}$ MAFESOLI, 1995, 1998), através da temática da violação dos Direitos Humanos. Sendo uma pesquisa qualitativa de revisão bibliográfica dos artigos publicados pelo Grupo. Nos resultados percebe-se o entrecruzamento da multiplicidade de percepções dos sujeitos e do objeto de pesquisa configurando o corpus pesquisador dentro da concepção de transversalidade.

Palavras-chave: Pesquisa qualitativa; Cotidiano; Bullying; Ensino.

\begin{abstract}
The article is an analysis of the scientific articles published by the IFMT Research Group on Humanities and Contemporary Society (GPHSC-IFMT), the cutoff between 2016 and 2017, and analyzed how the research conducted by the research group They are part of the proposition of multiple approaches of bullying in daily school life (CERTEAU, 1994 and MAFESOLI, 1995, 1998), through the theme of violation of Human Rights. Being a qualitative research of bibliographic review of the articles published by the Group. The results show the intersection of the multiplicity of perceptions of the subjects and the research object configuring the researcher corpus within the concept of transversality.
\end{abstract}

Keywords: Qualitative research; Daily life; Bullying; Teaching. 


\section{INTRODUÇÃO}

Este artigo apresenta a compreensão sobre o viés epistemológico da pesquisa qualitativa como resultado dos debates e intervenções críticas do Grupo de Pesquisa em Humanidades e Sociedade Contemporânea do IFMT (GPHSC-IFMT), a partir das pesquisas realizadas, entre os períodos de 2016 e 2017, com o recorte temático: bullying e violação dos Direitos Humanos; visando a compreensão das publicações realizadas pelo grupo de pesquisa através dos percursos investigativos qualitativos educacionais e no cotidiano dos estudantes do Ensino Médio e Técnico Integrado, do Estado de Mato Grosso, Brasil.

O GPHSC-IFMT, fundado desde 2008, com a motivação de um Grupo de professores de filosofia da cidade de Cuiabá, Mato Grosso, do Centro Federal Tecnológico de Mato Grosso (CEFET-MT), hoje IFMT (Instituto Federal de Educação, Ciência e Tecnologia de Mato Grosso). Com o tempo, foram integrados ao Grupo pesquisadores e técnicos de outras áreas de atuação; as reuniões centralizaram-se no campus Cuiabá Bela Vista do IFMT, localizado na cidade de Cuiabá, Mato Grosso. Um marco importante da história do grupo de pesquisa aconteceu em 2016, já no segundo semestre, com a expansão do GPHSC-IFMT para outras territórios e cidades do Estado de Mato Grosso. Atualmente, o grupo conta com pesquisadores de outros Estados e instituições (IFSP, IFMG, IFPB, UFMG e escolas da rede estadual e municipal de Mato Grosso).

O Grupo é formado por profissionais de áreas diversificadas que atuam na área da educação, como professores, técnicos e alunos bolsistas e voluntários, que se destacam por pertencerem a múltiplos espaços das ciências humanas e sociais, ciências naturais e exatas; o que justifica a sua transversalidade no processo de utilização da investigação qualitativa. Com objetivo de interpretar a sociedade contemporânea a partir de diferentes concepções teóricas e de autores, descrevendo e analisando de ângulos diferentes os mesmos fenômenos. Em outros termos, o GPHSC-IFMT, coerente com sua estrutura multidisciplinar, produz diferentes recortes de um mesmo sujeito pesquisado, buscando encontrar, na diversidade de experiências e visões teóricas de seus pesquisadores, os conceitos e métodos adequados a uma compreensão interdisciplinar do fenômeno contemporâneo estudado, trazendo como resultados múltiplos olhares sobre o mesmo sendo a perspectiva transdisciplinar do grupo, que abarca pessoas de formações diversas e amplas.

Todavia, para além da multidisciplinaridade que nos leva em direção às experiências interdisciplinares de produção de conhecimento, a perspectiva que orienta o grupo é transdisciplinar e de transversalidade, ou seja, parte do pressuposto epistemológico de que a 
realidade social é constituída por diferentes níveis em coexistência, e nas relações intrapessoais e interpessoais se configura um meio de conexão entre esses diferentes níveis de realidade.

Atualmente, o GPHSC-IFMT, possui três linhas de pesquisa, sendo elas: - Ciência, trabalho e tecnologia; - Filosofia Política; - Vulnerabilidades Sociais, Educação e Direitos Humanos. Ao final do ano de 2015, esta última linha, ao debater sobre as questões dos Direitos Humanos e as violências no cotidiano escolar, percebeu a relevância da temática bullying e iniciou-se a constituição de um projeto de pesquisa para investigar a recorrência da violência escolar, a escolha da investigação qualitativa oferece oportunidades aos pesquisadores para compreender a sua prática na atuação do cotidiano escolar e as subjetividades que estão presente neste espaço de ensino e aprendizagem. Os enfrentamentos das violências nas escolas são metas necessárias para educação que, nos últimos anos, levando em consideração os fatos que vem ocorrendo dentro dos muros das instituições, sejam elas públicas ou privadas, este é um problema que já não está distante da realidade do cotidiano escolar, sendo premente investigálo. A partir dos fatos apresentados acima, que se faz a análise da pesquisa qualitativa na trajetória de pesquisa do Grupo desenvolvida a partir da noção de cotidiano escolar e das suas relações com a violência escolar.

No presente artigo, objetivou analisar as pesquisas realizadas pelo grupo de pesquisa sobre o tema bullying e o cotidiano escolar (CERTEAU, 1994 e MAFESOLI, 1995, 1998), percebendo o viés epistemológico de observação do fenômeno da violência escolar imersa no cotidiano; em que os pesquisadores procuram compreender as relações existentes entre os mesmos, configurando a noção de cotidiano escolar como pano de fundo do cenário social em que o fenômeno ocorre, bem como o escopo metodológico para realização da própria pesquisa.

A partir da leitura dos textos publicados, procuramos perceber as principais temáticas, autores e contribuições dos mesmos; ressaltando a relação com a abordagem do cotidiano escolar, apontando as principais contribuições dos mesmos, as possíveis lacunas; e como a temática abordada têm sua interpretação ampliada quando o foco está no cotidiano escolar.

\section{REFERENCIAL TEÓRICO}

Quando um pesquisador tem como referência, em relação ao seu objeto de pesquisa, o cotidiano escolar; isso não implica uma investigação qualitativa das atividades envolvidas, como um estudo de uma rotina, repetição de atividades ou monotonia. $\mathrm{O}$ olhar procura observar o cotidiano nas nuances que o constitui, desde atividades rotineiras e ordinárias às inquietações 
e aos conflitos. Estes últimos não são negados ou ignorados, como se constituíssem espaços instáveis, que se destoam do que se tem como diretrizes e referenciais educacionais.

Esta perspectiva, em termos de pesquisa, se constitui em uma percepção de que as mudanças são fundamentais para a valorização de uma formação cidadã, inclusiva, plena, integral e humanizada. Origina-se nesta percepção um ponto de encontro do pesquisador com o cotidiano estudado, fazendo com que o mesmo seja compreendido uma vez que, "o cotidiano só é possível de ser entendido se for vivenciado, participado e partilhado com os sujeitos que vivem e fazem esse cotidiano acontecer, viver o cotidiano é conviver com suas experiências" (FERRAÇO, et al, 2008).

A desvalorização dos fenômenos, e da própria condição investigativa do cotidiano pela simples natureza do "conhecimento comum", ou seja, das questões cotidianas não possuírem valores científicos. E, ainda na pós-modernidade as investigações qualitativas do cotidiano são subjugadas como uma pesquisa não válida, e muitas vezes depreciadas por questões puramente mercadológicas, podemos verificar esta afirmação num simples levantamento exploratório descompromissado nos relatórios de prestação de contas das Instituições brasileiras responsáveis pelo fomento científico no país. Notamos que as dicotomias modernistas ainda estão implícitas no pensamento científico da contemporaneidade, ou seja, a "sede" quantitativa ainda "assombram" os nossos caminhos como pesquisadores e os objetivos das pesquisas qualitativas educacionais.

\begin{abstract}
A ambivalência de sentimentos perpassa o modo como se interpreta e, até mesmo, as tentativas de situar o fenômeno em suas plurais manifestações. Em variados espaços, sejam nos meios acadêmicos e nos "mass media", produzem-se relatos sobre os embates surgidos nas relações sociais das pessoas, sejam nos macros espaços, em locais mais restritos como a escola e nesta, a relação ocorrida entre professores e alunos em seu cotidiano (OLIVEIRA, 2017, p. 48).
\end{abstract}

Na concepção conceitual do sociólogo Michel Maffesoli (1995), o "quotidiano" é um conceito não muito utilizado pelos intelectuais, e se constitui como um estilo em seu sentido do termo dado pelo autor, ou seja, é algo abrangente, ambientado, que é a causa e o efeito, e em determinado momento a respeito das relações sociais em seus conjuntos.

\footnotetext{
(...) o quotidiano não é um conceito que se pode, mais ou menos, utilizar na arena intelectual. É um estilo no sentido que dei a esse termo, isto é, algo de abrangente, de ambiente, que é a causa e o efeito, em determinado momento, das relações sociais em seu conjunto. Dizendo em outros termos, o ar do tempo e a vida sem qualidade são reconhecidas no concreto, porque esse concreto é vivido como totalidade (MAFFESOLI, 1995, p. 64).
}

São nas práticas cotidianas, Certeau (1994, p. 109), que estão expressas a dependência de um grande conjunto, que é difícil de delimitar, e a título provisório, se pode designar como 
procedimentos. São também esquemas de operações e manipulações técnicas. De uma maneira mais simples a ciência é uma cristalização do saber disperso na vida através do cotidiano (MAFFESOLI, 1998), e que o mesmo deve ficar encarnado na realidade empírica do processo investigativo.

\begin{abstract}
Com efeito, ainda que isso seja esquecido com demasiada frequiência, a ciência não é senão a cristalização de um "saber disperso na vida, através do mundo cotidiano". Esta fórmula de Simmel indica bem, ao mesmo tempo, a ambição e a modéstia de toda progressão de conhecimento. Ele deve ficar, antes de mais nada, encarnado na realidade empírica (MAFFESOLI, 1998, pp. 47-48).
\end{abstract}

Ainda nos conceitos maffesolianos (MAFFESOLI, 1995, p. 65), pode-se dizer que a vida cotidiana é um excelente revelador do estilo de uma época, pois destaca a existência que é determinada pelo sentido coletivo, isto é, por meio de constrangimentos de seus usos e costumes, do habitus, toda a vida individual é limitada, mas ao mesmo tempo é a limitação que lhe permite existir.

Nesse sentido, a vida quotidiana é essa "centralidade subterrânea", esse ponto nodal, ao qual se pode não dar atenção, que se pode esquecer ou negar, mas que nem por isso deixa de constituir o húmus a partir do qual irá crescer toda a vida individual (MAFFESOLI, 1995, p. 65).

As vivências do cotidiano fazem com que se pense além do que está escrito em documentos oficiais e seja tecida uma rede de relações entre os sujeitos envolvidos no processo de ensinar e aprender "Assim, a tarefa que nos cabe é bem a de voltar a essa vida vivida ou mais próxima, a essa empiria; para retomar uma expressão da fenomenologia, “à própria coisa”. É isso que pode fazer com que apreciemos o hedonismo cotidiano" (MAFFESOLI, 1998, p. 46).

Certeau (1994), compreende essa dinâmica como práticas invisíveis, pois entende que os sujeitos que vivenciam o cotidiano escolar criem suas táticas e "maneiras de fazer", que abrem espaços e canais de reflexão e compreensão sobre as problemáticas e os conflitos existentes para agir no seu contexto da maneira que lhes é própria, observando as multiplicidade e complexidade das relações estabelecidas entre os sujeitos que fazem parte do cotidiano escolar.

A tessitura do cotidiano, é praticada a partir das vivências e das reflexões sobre os acontecimentos, o que Certeau (1994, p. 19-20), chama de táticas de praticantes, que proporciona o encontro entre as produções sociais e a subjetividade que nela existe, na qual os sujeitos se fortalecem e encaminham propostas para as mudanças de suas condições sociais.

A partir da observação do cotidiano escolar que o Grupo de Pesquisa percebeu que o fenômeno bullying e outros tipos de violações de direitos precisam ser discutidos pelos sujeitos 
participantes do cotidiano escolar, buscando estratégias de enfrentamento e melhoria do clima escolar.

Pensar em estratégias astutas para assegurar uma convivência de respeito e reciprocidade no ambiente escolar, onde a multiculturalidade, os diversos saberes e as individualidades estão presentes, pode ser uma forma de intervenção institucional para o combate ao bullying e outras formas de violências presentes no cotidiano escolar. O conflito de diversas ordens nos faz buscar outros cotidianos, que podem ser construídos/tecidos por meio de diálogos e pensamentos críticos, que promovem a tão desejada mudança.

Observando um cotidiano escolar que apresenta paradoxos educativos, o qual, ao mesmo tempo, nos fez refletir sobre o valor e a importância da escola para que ocorra a tão desejada transformação social, que percebemos estar pautada em reproduções e rigidez de suas práticas. Trabalhar no contexto deste cotidiano escolar com vivências conflituosas nos proporciona tomar decisões em um campo de grande complexidade, dúvidas, subjetividades e de conflitos de valores.

A necessidade de ruptura com modelos legitimados historicamente de uma escola excludente e polarizada, nos remete a vivenciar um cotidiano escolar, que seja construído a partir de relações saudáveis e de respeito aos Direitos Humanos, sendo ousado e muitas vezes subversivos, para que a tão esperada transformação ocorra, é necessário dar vez e voz aos sujeitos, na qual os mesmos abandonem suas certezas e convicções para que os saberes sejam (re)construídos através de táticas e subversões dos movimentos no "campo de ação do inimigo, e no espaço por ele controlado. Ela não tem, portanto, a possibilidade de dar a si mesma um projeto global nem de totalizar o adversário num espaço distinto, visível e objetivável" (CERTEAU, 1994, p. 101).

É fundamental que nas instituições escolares pensemos em educar para a vida (ZABALA, 1998), para a igualdade e para o respeito, rompendo com modelos competitivos, ameaçadores, tensos e controlados pelo medo, ou seja, "Por trás de qualquer proposta metodológica se esconde uma concepção de valor que se atribui ao ensino, assim como certas ideias mais ou menos formalizadas e explícitas em relação aos processos de ensinar e aprender” (ZABALA, 1998, p. 27).

É conveniente lembrar um termo que ultimamente tem sido usado no mundo todo, o bullying. Embora não seja um fenômeno novo, pois é do conhecimento de todos que sempre existiu dentro da escola, o termo pertence à língua inglesa, passou a ser usado no Brasil recentemente e tem sido objeto de estudos acadêmicos. O vocábulo só se tornou conhecido no 
Brasil por conta dos estudos acadêmicos iniciados a partir da década de 1970, nos Estados Unidos.

O significado da palavra bullying está relacionado com situações de abuso e de intimidação que ocorrem dentro ou fora da escola, ou seja, se refere a todas as formas de atitudes agressivas, verbais ou físicas, intencionais e repetitivas com o objetivo de intimidar ou agredir outra pessoa sem que esta tenha a possibilidade ou capacidade de se defender. Isso ocorre em uma relação desigual de forças ou poder (ELJACH, 2011).

No espaço escolar, Lemos (2007), essas formas de agressão são dissimuladas e têm consequências graves, pois os danos na vida dos envolvidos são irrecuperáveis e podem “destruir-lhes a saúde psicológica e física, além de consequências como rebaixamento da autoestima, depressão e marginalização que pode estimular desejos e (atitudes) de suicídio e assassinatos" (LEMOS, 2007, p. 68).

A discriminação é o pano de fundo do bullying nas relações de sociabilidade no cotidiano escolar. Esse é um dos maiores desafios na luta pelos direitos humanos; e, é ao mesmo tempo um problema que acreditamos ser de todos. Fica óbvio que as atitudes discriminatórias das crianças e jovens são imitadas e aprendidas no mundo adulto, no ambiente em que eles se desenvolvem onde vivenciam situações de abuso de poder, desigualdades e violações dos direitos.

A Lei $n^{\circ} 13.185$ (2015), que estabelece o Programa de Combate à Intimidação Sistemática (bullying) em todo o Brasil, traz alguns objetivos do programa de combate à intimidação dentre alguns temos: a prevenção e o combater a prática da intimidação sistemática (bullying) em toda a sociedade; a capacitação docente e das equipes pedagógicas para a implementação das ações de discussão, prevenção, orientação e solução do problema; a instituir as práticas de conduta e orientação de pais, familiares e responsáveis diante da identificação de vítimas e agressores; a assistência psicológica, social e jurídica às vítimas e aos agressores; promover medidas de conscientização, prevenção e combate a todos os tipos de violência, com ênfase nas práticas recorrentes de intimidação sistemática (bullying), ou constrangimento físico e psicológico, cometidas por alunos, professores e outros profissionais integrantes de escola e de comunidade escolar. 


\section{METODOLOGIA}

O texto procura abordar o processo de construção do objeto de pesquisa bullying e direitos humanos na educação; e a atuação do grupo pesquisador GPHSC-IFMT em um viés transversal na compreensão deste fenômeno.

A pesquisa de revisão dos artigos publicados pelo Grupo de Pesquisa em aporte qualitativo e fenomenológico, tem como procedimento o júri de especialistas (FERNANDES, 2012; ANDRADE, 2007); que através da atuação direta ou indiretamente no tema, apresenta reflexões sobre o mesmo e uma análise das produções. Esta metodologia utiliza a noção de partilha, de Hannah Arendt (2001), num movimento intrapessoal e interpessoal que estabelece uma relação viva com o contexto abordado.

As produções do grupo de pesquisa que utilizaram reportam ao recorte temático abordado e à concepção epistemológica pretendida, durante o período de 2016 a 2017, são as que seguem referenciadas ao final do texto. A partir da leitura das mesmas, buscou-se compreender as vertentes epistemológicas e metodológicas presentes, bem como, observar como a pesquisa qualitativa no cotidiano escolar se realiza. Sendo assim, a metodologia adotada se constitui nas etapas de pesquisa: - foram selecionadas todas as produções do grupo de 2016 e 2017 que versam sobre bullying e cotidiano escolar (identificado através da presença de ambos os termos no título e/ou palavras-chave); - organizadas em um quadro comparativo, identificando referencial teórico, metodologia e resultados; - e, por fim, analisados os textos selecionados, dentro da perspectiva de compreensão da constituição ou não de um perfil epistemológico de abordagem de pesquisa do grupo.

\section{RESULTADOS}

Pensar em estratégias astutas para assegurar uma convivência de respeito e reciprocidade no ambiente escolar, onde a multiculturalidade, os diversos saberes e as individualidades estão presentes, pode ser uma forma de intervenção institucional para o combate ao bullying e outras formas de violências presentes no cotidiano escolar. Os conflitos de diversas ordens nos fazem buscar outros cotidianos, que podem ser construídos/tecidos através de práticas como o diálogo e o pensamento crítico.

Analisamos o cotidiano escolar a partir da "prospectiva" apresentada pelos paradoxos educativos, no qual nos faz refletir sobre o valor e a importância da escola para que ocorra a tão desejada transformação social, ainda se pauta em reproduções e rigidez de suas práticas, sendo 
contraditória em sua razão de ser, promovendo aproximação/afastamento, acolhimento/exclusão, valorização/marginalização.

O atual modelo educacional que temos está em processo de reconstrução, abandonado uma postura passiva, em direção à manifestação do desejo por uma participação ativa e interativa na sociedade. É essa crise que desafia as estruturas escolares, na construção de novos perfis e nas mudanças de seus paradigmas, na qual diversa e multidisciplinar não cabe mais uma reprodução de um modelo.

A escola deve ser compreendida ao contrário desta representação educativa reduzida, ou seja, deve ser provocada a exercer sua função social (ZABALA, 1998), como protagonista de uma nova história “A capacidade de uma pessoa para se relacionar depende das experiências que vive, nesta época, para se estabelecer vínculos e relações que condicionam e definem as próprias concepções pessoais sobre si mesmo e sobre os demais" (ZABALA, 1998, p. 27).

Muitos conflitos gerados no cotidiano escolar partem do desrespeito à diversidade sociocultural, de gênero, raça e religião, e o bullying emerge como um fenômeno que desencadeia processos excludentes e traumáticos para muitos adolescentes em fase escolar, demandando da escola práticas e concepções que sejam pautadas na educação para a cidadania.

A pesquisa atual do GPHSC-IFMT, objeto de análise deste artigo, tem como título: "Violação dos Direitos Humanos e Bullying no contexto escolar: diagnóstico e proposta de intervenção com base no empoderamento dos alunos", aprovada pelo Comitê de Ética em Pesquisa (CAAE: 60165016.0.0000.5165) e encontra-se em andamento desde agosto de 2016 e encerrará em Agosto de 2018. A fase inicial da pesquisa permitiu um diagnóstico sobre violação dos Direitos Humanos e Bullying em sete escolas.

Segundo Bogdan \& Biklen (1994, p.11), a influência dos métodos qualitativos nas pesquisas de questões educacionais é cada vez maior. E muitos dos investigadores educacionais manifestam-se com uma atitude positiva face às mudanças que se têm verificado nas estratégias de investigações, contemplando a abordagem qualitativa tanto a nível pedagógico como a nível de condução de investigação.

Segundo Bauer e Gaskell (2003), entre as características da investigação qualitativa destacam-se a busca pelos significados que os sujeitos pesquisados atribuem às suas próprias ações, o caráter descritivo de apresentação, o uso de métodos de observação participante, a formulação de questões abertas nas entrevistas, entre outras.

No caso específico da pesquisa "Violação dos Direitos Humanos e Bullying no contexto escolar: diagnóstico e proposta de intervenção com base no empoderamento dos alunos" 
utilizamos de relações quantitativas para construir noções gerais sobre os sujeitos pesquisados e das questões abertas do questionário e a observação in loco do comportamento desses sujeitos. Numa primeira etapa, o estudo foi dirigido por meio de um questionário com quinze questões, treze fechadas e duas abertas, que nortearam o recolhimento das informações e permitiram a caracterização dos sujeitos pesquisados e do contexto social no qual estão inseridos.

As dez primeiras questões buscaram recolher informações gerais sobre os alunos (idade, sexo, orientação sexual), a escolaridade dos pais e a situação familiar (casa própria, trabalho). A questão seguinte foi subdividida em vinte e quatro itens que tem como objetivo identificar as formas de bullying sofridas ou praticadas pelos alunos. Duas outras questões objetivaram verificar se os alunos sofriam ou praticavam bullying sobre os colegas e os motivos relacionados a essa prática. Quanto às questões abertas: a primeira pede que o aluno que já sofreu ou viu alguém sofrer bullying faça um relato do ocorrido, enquanto a outra solicita sugestões dos alunos para acabar com o bullying.

Dos dezessete trabalhos desenvolvidos entre 2016 e 2017, dois foram apresentados no CIAQ, em Salamanca/Espanha (MOTA, et alli, 2017a; OLIVEIRA, C. E., et ali, 2017); sendo um deles específico sobre as questões teóricas sobre a pesquisa qualitativa em educação, o qual foi ampliado e publicado como artigo na revista Indagatio Didactica, em que a tônica do mesmo traduz, em linhas gerais, a perspectiva metodológica do GPHSC-IFMT.

\footnotetext{
O propósito desse artigo foi o de sintetizar algumas discussões sobre cientificidade e sobre pesquisa qualitativa que vem sendo realizadas no percurso das experiências dos pesquisadores do Grupo de Pesquisa Humanidades e Sociedade Contemporânea do IFMT (GPHSC-IFMT). Sobre o debate que se instalou nas ciências humanas e na educação quanto à pertinência, adequação ou inadequação dos métodos quantitativos e qualitativos nos processos de validação de suas pesquisas, acolhemos a ideia kantiana, também defendida por outros autores, de que o quantitativo e o qualitativo são inerentes à própria manifestação dos fenômenos na consciência. Tomando, portanto, como referência um grupo específico de pesquisadores foi possível observar que a oposição entre a pesquisa quantitativa e a pesquisa qualitativa constitui-se em um falso dualismo (MOTA, et al, 2017b, p. 95).
}

A partir dos quinze trabalhos apresentados nos eventos, que discorreremos nossa compreensão sobre a pesquisa qualitativa no cotidiano escolar. Destes quinze, dois são resumos expandidos e os demais são artigos. Os trabalhos foram apresentados em eventos nacionais e internacionais; abordaram bullying e/ou violação dos Direitos Humanos (10); a violência escolar (2) e questões sobre Direitos Humanos (2). Dez destes trabalhos remetem diretamente ao cotidiano escolar, desde o título, palavras-chave ou no próprio texto; utilizando termos tais como: contexto escolar, cotidiano escolar, vivência, cotidianidade. 
Os trabalhos fazem também recortes específicos a partir da abordagem geral sobre: gênero, diversidade, uso do nome social, formação humana, identidade, sociabilidade, ensinoaprendizagem; dentre estes predominam: gênero, identidade. As pesquisas se localizam como pesquisas qualitativas, mesmo quando apresentam dados quantitativos, que são interpretados qualitativamente. Utilizam-se da abordagem fenomenológica, a análise do discurso e a análise do cotidiano.

Vale a pena ressaltar, que em se tratando de um grupo pesquisador, o processo de construção dos instrumentos de pesquisa, aplicação e interpretação, foi realizado em conjunto e em sub-grupos; sendo as publicações compostas por grupos de autores diferentes, com formação e titulação diferente, dentre especialistas, mestres, mestrandos, doutores; das diversas áreas das ciências humanas: filosofia (2), ciências sociais, letras (3), pedagogia, comunicação social, psicologia, serviço social; o que permitiu uma observação multidisciplinar do cotidiano escolar.

No artigo Violação dos direitos humanos e bullying no contexto escolar: uma realidade que precisa ser enfrentada (SILVA, V. C. G, et alli, 2016), enquanto primeira produção do grupo sobre o tema, buscou promover a reflexão sobre a importância de conhecer e confrontar as violações dos direitos humanos no contexto educacional e perceber como estas alcançam um certo status de legitimação e legalização, cuja banalização da violência faz com que os atos de agressão não sejam contestados.

Já entre os últimos trabalhos publicados (MOTA, R. M. F.; FONSECA, F. B.; OLIVEIRA, C. E.; ASSUMPCAO, Y. O., 2017), o estudo observou as relações humanas e sociais no limiar deste século, em que, mesmo diante dos avanços em relação aos Direitos Humanos, paradoxalmente, no meio escolar, são recorrentes a violação dos Direitos Humanos e os casos de bullying. De um modo geral, os resultados qualitativos apontam para uma necessária renovação do cotidiano escolar, nos âmbitos sociais, culturais e educacionais.

\footnotetext{
Não possui um sentido determinado, mas sentidos que ao mesmo tempo são postos à prova e vividos a medida que vão surgindo, como nos relatos dos alunos e alunos sobre a violação dos direitos e o bullying no ambiente escolar, surgem as várias formas de como estes fenômenos se apresentam: características físicas, sexualidade, racismo, agressões físicas e verbais; e a ambiguidade dos discursos, que possui características de violação dos direitos humanos, mas não se situam como protagonistas (OLIVEIRA \& MOTA, 2017, p. 08).
}

Neste artigo e nos demais podemos perceber as implicações das situações de bullying e violação dos direitos humanos nas mais diferentes manifestações cotidianas, inclusive de forma velada nos discursos. 


\section{CONSIDERAÇÕES FINAIS}

Diante desse quadro, percebe-se que a violação dos Direitos Humanos nas cotidianidades escolares é uma prática comum. Considerando que o conceito de Direitos Humanos é definido como todos aqueles direitos que os seres humanos têm, única e exclusivamente, por terem nascidos e por serem parte da espécie humana. Eles foram firmados na Declaração Universal dos Direitos Humanos, assinada em 10 de dezembro de 1948, em Paris, pelos povos do mundo todo por intermédio dos chefes de Estado. Esses direitos são baseados em princípios éticos, morais e se reconhece que a diversidade é a única coisa que todos os seres humanos têm em comum e que deve ser respeitada e tratada com equidade.

Em termos de uma compreensão qualitativa a partir do cotidiano escolar, percebe-se que vários foram os autores utilizados e que alguns artigos focam de forma mais específica este cotidiano, alguns usam o termo mas não se aprofundam na cotidianidade. Contudo, o fato de trazerem a pesquisa para um âmbito atual e vivencial deve ser ressaltado. O cotidiano é percebido por alguns de modo social ou educacional; outros de modo vivencial, e outros ainda o foco é discursivo; de modo que as produções se complementam.

O grupo percebe a importância de divulgar os resultados desta pesquisa a toda comunidade escolar e, também, a necessidade de ações para o combate e amenização do problema que atinge nossas escolas; sendo a última fase da pesquisa, a atuação participante nos contextos abordados.

\section{REFERÊNCIAS}

ANDRADE, Daniela. O Lugar do Feminino. Cuiabá/MT: EduUFMT/FAPEMAT, 2007.

AREND, Hannah. A Condição Humana. 10 ed. Rio de Janeiro: Forense Universitária, 2001.

BAUER, Martim; GASKELL, George. Pesquisa Qualitativa com texto, imagem e som um manual prático. Editora Vozes: São Paulo, 2003.

BOGDAN, Robert. BIKLEN. Sari. Investigação qualitativa em educação. Porto: Porto Editora, 1994.

BRASIL. Presidência da República. Casa Civil. Subchefia para Assuntos Jurídicos. Lei no 13.185, de 6 de novembro de 2015. Institui o Programa de Combate à Intimidação Sistemática (Bullying). Brasília: DOU, 9.11.2015. Disponível em:

<http://www.planalto.gov.br/ccivil_03/_Ato2015-2018/2015/Lei/L13185.htm>. Acesso em: 02 set. 2018.

CERTEAU, Michel. A invenção do cotidiano: artes de fazer. Petrópolis: Vozes, 1994. 
ELJACH, S. Violencia escolar en América Latina y el Caribe Superficie y fondo. República de Panamà: UNICEF, 2011.

FERNANDES, Raquel Martins. O Olhar, A Menina dos Olhos, Única e Total: compreensão fenomenológica do Programa Meninas dos Olhos de Deus e das dimensões da Exploração Sexual Comercial de Crianças e Adolescentes em interface com a educação. Orientador: Dr. Luiz Augusto Passos. Tese (doutorado) - Universidade Federal de Mato Grosso, Instituto de Educação, Programa de Pós-Graduação em Educação, Cuiabá., 2012.

FERRAÇO, Carlos. Cotidiano escolar, formação de professores (as) e currículo. São Paulo: Cortez, 2005.

LEMOS, Anna. Uma visão psicopedagógica do bullying escolar. Rev. Psicopedagogia. 2007; 24(73): 6875

MAFFESOLI, Michel. A contemplação do mundo. Porto Alegre: Artes e ofícios Editora, 1995.

MAFFESOLI, Michel. Elogio da razão sensível. Trad. Albert Christophe Migueis Stuckenbruck. Petrópolis, RJ: Vozes, 1998.

MOTA, Raquel; SOUZA, Jair; OLIVEIRA, Paulo; NEIVA, Marcos; ALMEIDA, Rodney; FONSECA, Felicissimo (2017). Pesquisa qualitativa em Educação: estudos transdisciplinares do Grupo de Pesquisa Humanidades e Sociedade Contemporânea do IFMT (GPHSC-IFMT). INDAGATIO DIDACTICA., v.9 (3), novembro 2017, p.79 - 98, 2017. Recuperado de http://revistas.ua.pt/index.php/ID/article/view/6056.

OLIVEIRA, Eliane. Imaginários de violências e conflitos na relação professor/aluno. (Dissertação de mestrado). Universidade Estadual do Oeste do Paraná - Unoeste, Cascavél, PR, Brasil, 2017.

OLIVEIRA, Inês B. Criação curricular, autoformação e formação continuada no cotidiano escolar. In.: Ferraço, Carlos Educardo (Org.). Cotidiano escolar, formação de professores(as) e currículo. São Paulo: Cortez, 2005.

SILVA, Vanessa Costa Gonçalves. Violência escolar, bullying e violação de direitos humanos no cotidiano escolar. Dissertação (Mestrado Acadêmico em Ensino). Instituto Federal de Educação Ciência e Tecnologia de Mato Grosso. Cuiabá, 2019.

ZABALA, Antoni. A prática educativa: como ensinar. Porto Alegre: Artmed, 1998.

Recebido em: 16 de outubro de 2019.

Aprovado em: 18 de janeiro de 2020. 